\title{
Dimensões geosimbólicas do sexo tarifado entre homens: discussões provenientes de uma etnografia urbana
}

\section{Geo symbolic dimensions of tariffed sex between mens: discussions from an urban ethnography}

\section{Dimensiones geosimbólicas del sexo tarifado entre varones: discusiones desde una etnografía urbana}

\section{Cristiano Hamann*}

Universidade Federal do Rio Grande do Sul - UFRGS, Porto alegre, Rio Grande do Sul, Brasil

\section{Adolfo Pizzinato **}

Universidade Federal do Rio Grande do Sul - UFRGS, Porto Alegre, Rio Grande do Sul, Brasil

\section{Kátia Bones Rocha ***}

Pontifícia Universidade Católica do Rio Grande do Sul - PUC-RS, Porto Alegre, Rio Grande do Sul, Brasil

\begin{abstract}
RESUMO
A presente comunicação tem por objetivo apresentar articulações teóricas e metodológicas, assim como os principais resultados de uma Dissertação de Mestrado em Psicologia Social sobre prostituição entre homens em Porto Alegre (RS/Brasil). Trata-se de uma pesquisa realizada em dois processos vinculados e indissociáveis: uma incursão etnográfica por lugares de prostituição na cidade e oito entrevistas narrativas com homens que se dedicam a este fazer, gerentes de estabelecimentos e promotores de festas. A Dissertação apresenta-se como resultado da produção de conhecimento em sintonia com os Estudos de Gênero, aderindo a uma perspectiva interseccional e em um processo de aproximação com a noção de Comunidades de Prática.
\end{abstract}

Palavras chave: gênero, sexualidade, etnografia, prostituição masculina.

\section{ABSTRACT}

This communication aims to present theoretical and methodological articulations, as well as the main results, of a Master Dissertation in Social Psychology about male prostitution in Porto Alegre (RS / Brazil). This is a survey conducted in two linked and interrelated processes: an Ethnographic incursion by male prostitution places in the city and eight narrative interviews with men who are engage in prostitution, business managers and party promoters. The dissertation is presented as a result of knowledge production in line with Gender Studies, adhering to an intersectional 
perspective, in a process of approach with the notion of Communities of Practice.

Keywords: gender, sexuality, ethnography, male prostitution.

\section{RESUMEN}

Esta comunicación tiene como objetivo presentar tanto articulaciones teóricas y metodológicas, así como los principales hallazgos, de una investigación de maestría en Psicología Social acerca de la prostitución de hombres en Porto Alegre, (BR). Se trata de una investigación realizada en dos procesos vinculados e interrelacionados: incursión etnográfica en espacios de prostitución de hombres y entrevistas con hombres que se dedican a la prostitución, los gerentes de los establecimientos de prostitución y promotores de fiestas con estos fines. Los resultados de la investigación se presentan en sintonía con los estudios de género en la perspectiva interseccional, en un proceso de aproximación con el operador teórico de Comunidades de Prácticas.

Palabras clave: género, sexualidad, etnografía, prostitución de varones.

\section{I ntrodução}

Pesquisas normalmente associam prostituição a diferentes campos de produção discursiva: ou excludentes ou voltados à possibilidade de criações singulares de vida. Atentam tanto à questões que vinculam comércio e relações intersubjetivas (Burbulhan, Guimarães, \& Bruns, 2012); à contendas acirradas sobre suas implicações diante de concepções feministas (Daich, 2012; Piscitelli, 2012) e, especificamente no que concerne a este estudo, à experiência de homens neste fazer (Barreto, 2012; Cantalice Silva, 2009; Olivar, 2010; Perlongher, 2008; Pocahy, 2011; Souza Neto, 2009; Teixeira, 2011; Viana, 2010). Um aspecto que pode ser tomado como transversal nesta discussão é a percepção de que, entre os homens, circulam diferentes compreensões em relação às vivências na prostituição, podendo suscitar leituras de trabalho/ocupação ou de fazeres outros.

Como figura na literatura especializada (Hirata \& Kergoat, 2007) o trabalho no espaço público - usualmente reconhecido como trabalho produtivo - é atravessador das masculinidades e dos homens. Esta dimensão social de vinculação da prostituição, como reprodutiva, e intrinsecamente relacionada às mulheres, nos permite colocar em pauta indagações acerca da significação desta no itinerário de homens. Esta dimensão de análise convida, entretanto, que se discutam as estratégias desenvolvidas nesse fazer e saber dos homens, de modo a possibilitar compreensões acerca de aspectos subjetivos que circunscrevem esta experiência, permitindo pensar usos outros do corpo, nas entrelinhas do sistema capitalista e de suas culturas relacionais. 
Para o Ministério do Trabalho brasileiro (2014), a prostituição é reconhecida. Segundo a Classificação Brasileira de Ocupações, disponível no site do Ministério do Trabalho e Emprego (2014), a inclusão da ocupação Profissional do Sexo data de 22/10/2002. Tendo por sinônimos: Garota ou Garoto de programa, Meretriz, Messalina, Michê, Mulher da vida, Prostituta e Trabalhador do sexo. Este fazer compreende uma série de atividades que usualmente não referenciamos no cotidiano, como ligadas à ideia de prostituição. Para além da prática sexual com o(a) cliente, o Ministério indica que o trabalhador(a) do sexo cumpra certas prerrogativas que possam minimizar possíveis vulnerabilidades (Brasil, 2014). O Ministério indica como fatores de formação e experiência que, para o exercício profissional, os(as) trabalhadores(as) participem de oficinas sobre sexo seguro e que o acesso à ocupação seja restrito a maiores de dezoito anos. Ainda segundo a Classificação Brasileira de Ocupações (2014), são consideradas competências pessoais do profissional do sexo: demonstrar capacidade de persuasão e de comunicação; capacidade de realizar fantasias sexuais; demonstrar paciência; planejar o futuro; demonstrar solidariedade aos colegas de profissão; demonstrar capacidade de ouvir; demonstrar capacidade lúdica; demonstrar sensualidade; reconhecer o potencial do cliente; cuidar da higiene pessoal e manter sigilo profissional.

Para além do caráter genérico dos documentos legais, que podem cair numa disposição planificada e reducionista, estudos clássicos indicam a pluralidade das formas de se relacionar com a prostituição (Perlongher, 2008). Pensar a pluralidade de narrativas acerca deste fazer, e concomitantemente, nas formas de ser homem na contemporaneidade, mostra-se importante. Diante desta dimensão complexa, a perspectiva de estudo interseccional, proveniente do Feminismo negro estadunidense, critica a noção hegemônica de homens e masculinidade (Magliano, 2015; Piscitelli, 2008; Vigoya, 2008) e atenta para diversos marcadores de diferença, como, por exemplo, cor, idade, renda, escolaridade e território. Estes marcadores se expressam corporificados no cotidiano e localizam a prática do sexo tarifado - tomando aqui uma expressão já presente na literatura (Pocahy, 2011) - como um campo de diferenças e singularidades, confrontando diretrizes genéricas sobre as relações no mercado sexual, como a própria definição do extinto Ministério do Trabalho fazia em 2002.

O "tornar-se homem" sofreu um exercício de progressiva desnaturalização nesta área de conhecimento, seja pela via das reflexões acerca das provas cotidianas e ritos pedagógicos (Badinter, 1993), dos espaços de convivência e as construções subjetivas envolvidas (Welzer-Lang, 2001), ou da construção do "ser homem" como associada ao afastamento com o campo simbólico do feminino (Torrão Filho, 2005). Neste estudo assumiu-se a perspectiva de que, 
nos meandros deste "tornar-se homem", as formas de se construir demandam compreensões de gênero e sexualidade como fenômenos indissociados que são performatizados cotidianamente (Butler, 2002; Miskolci, 2012).

Considerando esta compreensão, de atravessamentos sociais como composições plurais e interconectadas, propomos um exercício de aproximação da perspectiva etnográfica e interseccional com a noção de Comunidades de Prática, tal como na análise proposta por Paechter (2003) e Wenger (2000). Para estes, as comunidades se organizam a partir de três eixos integrados: compromisso mútuo, ação conjunta e repertório compartilhado. Estas noções permitem que se compreenda o processo de constituição de uma comunidade como relação contextual de práticas, identificações e aprendizagens. Wenger (2000) considera que esses aspectos não supõem homogeneidade, podendo compor-se numa relação de complementariedade ou de parcialidade situada. Enquanto compromisso mútuo fala de uma rede de significados que se negocia mutualmente, a ideia de ação conjunta que compreende as práticas resultado da relação de responsabilidade mútua em determinada comunidade. De outra forma, o repertório compartilhado indica uma dimensão histórica de compromisso mútuo, concebida num conjunto de aspectos como discursos, conceitos, artefatos e estilos envolvidos nas práticas comunitárias. Partimos, portanto, da noção de comunidades de prática como fenômeno intrinsecamente relacionado à construção e manutenção de estratégias no âmbito do sexo tarifado exercido por homens, considerando que essa dimensão não se faz dissociada dos marcadores sociais de diferença e dos efeitos das configurações dos modos de vida capitalísticos (Streeck, 2012) evidentemente implicados nesses processos.

Com base nestas discussões prévias, esta investigação procurou contribuir para o desenvolvimento de compreensões acerca das significações e das práticas envolvidas no sexo tarifado realizado por homens. Procurou-se discutir a própria trilha geosimbólica elaborada na pesquisa, cujas articulações de marcadores de diferença percebidos permitiram analisar Comunidades de Prática específicas de sexo tarifado entre homens em Porto Alegre, assim como compreender aspectos discursivos relacionados a exercícios de sexualidade e identificações de gênero. Pretendeu-se, ainda, conhecer e analisar os sistemas de significação e de práticas que organizam as comunidades de sexo tarifado entre homens. As dimensões teóricas de análise articularam-se ao longo do trabalho realizado de modo a construir compreensões contextuais, situadas e parciais (Haraway, 1995) acerca do fenômeno.

A incursão em campo se deu pela via de informantes chave, contatados através da técnica de snowball. Inicialmente, um coordenador da área de DST/Aids e Hepatites Virais do Município de 
Porto Alegre indicou outro informante que exercia um cargo de gerência em uma sauna ${ }^{1}$ da cidade. Esses contatos, a cada nova entrevista, levavam a outros locais - cujo critério era fazer parte do itinerário dos entrevistados. Este processo de incursão, no qual as observações, os relatos no diário de campo e as entrevistas se tornaram indissociáveis, constituiu-se dos seguintes locais: uma rua, duas saunas, dois bares e uma danceteria. Entretanto, dado a necessidade de síntese e tempo disponível no desenvolvimento da pesquisa, foram escolhidos três locais que foram analisados em profundidade. Essa escolha, apesar de arbitrária, se faz pela maior permanencia nestes locais e pela característica de formaçao da rede de sexo tarifado construída em pesquisa.

\section{Apontamentos etnográficos}

A partir da análise dos diários de campo e das entrevistas realizadas figuraram alguns aspectos relativos aos itinerários diversos no sexo tarifado porto alegrense e comunidades de prática que circunscrevem o fenômeno na cidade. Marcadores como idade, escolaridade, cor e território, mesclam-se neste contexto - expressados em elementos que influem no sucesso ou fracasso das negociações na prostituição. Estes fatores mostram-se intrinsecamente associados à possibilidade de agenciamento dos homens envolvidos, organizando-se, em especial, nas temáticas relacionadas a códigos de conduta, as relações borradas entre sexo tarifado e certas formas de afeto, e, por fim, estratégias de engendramento nas relações de consumo.

No que se refere aos códigos de conduta, podemos notar que existe uma percepção de formas de tratamento e negociação apropriadas, variando conforme as particularidades do território. As diferenciações entre "profissionais" e "picaretas", entre "clientes bons" e "clientes ruins", por exemplo, indicam particularidades de percepção tanto sobre a dimensão da busca de com quem estabelecer negócio, como de uma maneira considerada mais ou menos adequada de fazê-lo. Essas expressões variaram conforme o local, sendo a "picaretagem" um marco mais expressivo no contexto da Rua, e as divisões entre clientes adequados ou inadequados mais presentes em locais fechados como bares e saunas.

$\mathrm{Na}$ esteira dessa discussão, percebemos que diferentes territórios são associados à qualidades e complicações, utilizados nas narrativas para distinguir e qualificar os homens que aderem a negociações nestes espaços, assim como suas formas de interação. A Rua é vista como local perigoso, de muita exposição e que parece não suscitar trocas protetivas entre os Garotos, ainda que figure como local de iniciação para alguns dos entrevistados. Em contrapartida, a Sauna mostra-se uma alternativa, numericamente, mais frequentada por 
clientes e, assim como o Bar, já denota formas de proteção no grupo de "garotos de programa" - manifestada, como dito anteriormente, na indicação de clientes mais ou menos adequados, estabelecimento de preços base e situações de confraternização fora do local de sexo tarifado. Essas caracterizações acerca de práticas adequadas ou não se mostram intrinsecamente relacionada às necessidades de funcionamento em espaços diferenciados - de modo que categorias mais focadas nos Garotos, como "picareta" ou profissional, compõem estratégias concernentes ao espaço mais precário em termos de segurança que é a Rua. Por outro lado, locais mais controlados, que não demandam tanto cuidado com a própria segurança e que se calcam na centralização de gerências de casas, possibilitaram como estratégia um maior escrutínio quanto ao "perfil ideal" da clientela.

Este aspecto nos faz atentar para a dimensão do marcador território no que concerne à conduta intragrupos, que culmina em controles de preços e formas de abordagem a clientes. Entretanto, suscita pensar também artimanhas vinculadas, por exemplo, nas combinações de tarifa, que mais facilmente se mostram ligadas a marcadores sociais para além do território: de aparência (não equivalente a uma noção genérica de idade), classe, "raça" e escolaridade. Esses marcadores complexificam a situação e indicam que uma leitura tomada somente a partir de território poderia mascarar a ligação dos outros marcadores de diferença na constituição de vínculos especialmente lucrativos, como os de "cliente fixo" 2 .

Vínculos com "clientes fixos" se mostraram mais prováveis para os homens que se aproximam de indicativos de aparência "jovem", masculina, viril, de certa estética que se manifesta em condutas corporais e de vestuário considerados mais próximos das representações de classe média, identificáveis dentro de uma noção de branquitude, de escolaridade elevada e de itinerário recente no sexo tarifado (ser "novo" esteve intrinsecamente vinculado a uma ideia de boa conduta e ingenuidade). A possibilidade de manutenção de uma clientela fixa, portanto mais segura e rentável, mostrou-se a meta para uma grande parte dos homens. Garotos que se identificaram em conversas e entrevistas como negros ou pardos, e que usualmente tinham como característica menor escolaridade e pior condição socioeconômica demonstravam uma maior permanência nos ambientes e maior dificuldade de estabelecer clientes fixos, de modo que certas hierarquizações sociais pareceram se manter - ainda que se manifestassem de maneiras singulares.

Neste contexto, as estratégias elencadas suscitam pensar uma relação de "vitrine" com o próprio corpo, em que as formas de consumo mostram a forte presença de códigos homonormativos nestes espaços de sociabilidade. Esse processo, e seus atravessamentos discursivos, é particularmente observável quando da manutenção de certas performances corporais tradicionalmente 
relacionadas a masculinidade no marco da heterossexualidade e nos conflitos decorrentes da procura de clientes fixos.

Para a grande parte dos entrevistados, a utilização de artimanhas de conquista de clientes fixos concorre, por vezes, com o temor de uma aproximação borrada entre trabalho e relação amorosa. Estas articulações entre afetividade e trabalho acabam por incitar uma gama de discussões jurídicas que consideram as possibilidades de legitimação de formas de ocupar-se para além de noções higienistas - que dissociam o trabalho legítimo de manifestações de afeto e prazer. De outra forma, também trazem à tona - herdando das esferas de discussão em que não se tem a pretensão de colocar o prazer ou o trabalho sob leituras higienistas - o anonimato e o sigilo como aspectos da vida que flertam com exercícios de sexualidade e as possibilidades de trabalho. No que concerne a esta questão, os entrevistados autodeclaravam-se heterossexuais e grande parte mantinha relações estáveis com mulheres - o que exigia, para muitos, uma relação de segredo acerca da prática da prostituição, ou formas de negociação nas quais as mulheres não só tinham conhecimento como participavam dos processos de negociação dos programas. Esta questão da participação das mulheres, em específico, faz atentar para uma atualização do marco da heterossexualidade como atrativo na prostituição, questão que merece maior detalhamento futuro.

\section{Síntese de elementos comunitários}

Em termos metodológicos, vimos que, a partir da incursão etnográfica e da análise de perspectiva interseccional que se encaminhava, a possibilidade de compreender as práticas exigia um olhar atento para as formas de constituição comunitária. Aderimos, portanto, a noção de Comunidades de Prática, tendo em vista que possibilitava uma visão localizada aos processos sociais que se engendravam entre os homens ${ }^{3}$. Entende-se que as relações constituídas nos locais poderiam ser abarcadas a luz de três categorias comunitárias: HST (homens que se dedicavam ao sexo tarifado), HST/Gerência e HST/Cliente. Estas dimensões foram elencadas, pois davam ensejo para formas de conduta e prática específicas.

Entre os HST em Bar e Sauna, por exemplo, evidenciava-se aspectos relativos à abordagem comum, às lógicas de sigilo e anonimato internas entre colegas, às negociações quanto ao cartel de valores e uso de força para firmar estas relações. Estas medidas não se atualizavam em locais como a Rua, de modo que o território se mostrava particularmente relevante quando dessas formas de organização. Além disto, nos ambientes fechados, um crivo moral de 
"bom colega" se mostrou presente, de modo que um aparato de boa conduta se mostrava permeando as formas de comunicação e de negociação entre esses homens. No contexto da comunidade HST/Gerência, a manutenção do bem-estar dos HSTs, a disposição de filmes heterossexuais, a realização de eventos e contatos no local de sexo tarifado, assim como as lógicas de vigilância e punição, foram marcantes. Através das entrevistas e observações, compreendemos existir uma tensão entre a dependência da Gerência para com o trabalho dos Garotos e um exercício de disciplinarização e moralização destes. Essa relação, em particular, põe em pauta a relação entre manutenção de casas de diversão e cafetinagem, processo negado pela Gerência - ainda que auxiliasse nas negociações com clientes.

No que concerne à dimensão HST/Clientes, condutas relacionadas às esferas clientes fixos, cliente eventuais ou clientes frequentes (cuja dimensão diferencial está principalmente vinculada a um espectro de maior ou menor "envolvimento afetivo" para a maioria dos participantes) delimitam sua lógica de interação - mas estão especialmente fundamentadas nas estratégias de sedução e performatividade romântica, como beijos, carícias e formas de companhia. Essas questões já foram alvo de pesquisas (Pocahy, 2011; Souza Neto, 2009), e reiteram um jogo de atualização e performance de amor romântico como parte intrínseca dos meandros da prostituição. No caso dos homens nesta investigação, esse jogo se mostra uma estratégia de captação de clientes - como declarado por um dos participantes que indica ser a "intimidade" e o "tratar com carinho" uma das táticas para conseguir e manter relações fixas.

As três dimensões elencadas, HSTs, HST/Gerência e HST/Clientes, oportunizaram uma visão que não compreendemos como deslocadas de uma intenção comum: a manutenção dos ambientes de sexo tarifado. Entretanto, cabe atentar que as dinâmicas estabelecidas reiteram corpos dignos de legitimidade e, portanto, consumíveis dentro desse espectro relacional. Discursos de essencialização vinculados a certa concepção de "alma de puta" 4 , à noção de quais prazeres são genuínos e legítimos, e a determinadas formas de ser e de aparentar - pela via do ser "homenzinho", ou "macho" - dão ênfase para as relações de poder nas quais estereótipos clássicos de virilidade e masculinidade estão presentes. Formas de dessexualização do cliente - como nos momentos em que HST ressaltam que seus clientes querem quase que exclusivamente uma relação de companheirismo e atenção -, por vezes mostram-se atuantes, operando certa dissociação entre orientação sexual e prática como forma de reiterar a heterossexualidade e virilidade. No que concerne, especificamente, a essa separação entre orientação sexual e prática, muitos dos entrevistados indicaram que a negociação do sexo se constituía de um processo erótico por si, em 
alguns momentos indicando que a própria materialidade do dinheiro ou a posição a ser ocupada como alvo do desejo alheio suscitava excitação. Ao mesmo tempo que este processo destituía de força a separação entre orientação e prática - movimento que pode ser compreendido como dissidente - atualizava, em diversos momentos das narrativas, discursos tradicionais de essencialização entre ser ativo/passivo, homem/viado.

\section{Conclusões}

Ao longo do trabalho de campo etnográfico e da escolha analítica pela via das Comunidades de Prática, pode-se elencar algumas dinâmicas na prostituição entre homens. A dimensão territorial esteve presente tanto no que concerne a organização das formas de conduta (abordagens e aproximações, como vimos, variaram conforme as organizações comunitárias e seus territórios) quanto às formas de controle que davam a estas condutas condições de possibilidade. Ainda no que concerne a território, vemos que noções como "picaretagem" e "profissionalismo" distinguem formas de significar e operar na prostituição. Além disso, esse marcador mostra-se estratégico no campo de estudos visto que, para além da questão simplesmente geográfica, a intersecção entre idade e território denotam atualizações pela via do "forasteiro" - o que se coaduna a toda uma rede discursiva indicativa de um campo de moralidade, ou seja, a prostituição corromperia quem estivesse muito tempo aderindo a suas práticas, de modo que o outsider é mais valorizado e possível de ser inscrito numa relação com clientela fixa. Podemos observar, por outra via, que as performances de amor romântico que caracterizavam as relações fixas se atualizam neste meio, de modo que compõem a rotina de trabalho/lazer de muitos homens.

Algumas dimensões do sexo tarifado entre homens nesta pesquisa merecem maior estudo. A forma difusa com a qual se dá a permanência dos boys/garotos de programa/profissionais do sexo indica um espaço de discussão não muito bem elaborado. Apesar de, usualmente, se compreender o fazer de homens no sexo tarifado como uma atividade mais instável e fluida do que das mulheres e travestis, aspectos como a busca por clientes fixos, o retorno periódico indicado pelos entrevistados aos locais de encontro, as formas de "apadrinhamento" das famílias e casais por clientes e o fato de ser a principal renda durante muitos anos indicam a necessidade de uma análise mais acurada. As formas de se relacionar com o sexo tarifado mostraram-se bastante diferentes.

A composição geosimbólica que figura no itinerário Rua/Sauna/Bar, também flerta com as possibilidades vistas pelo uso de aplicativos e mídias sociais, questão que pode ser elencada futuramente. O uso de 
mídias sociais, para alguns dos participantes da pesquisa, indicou uma aproximação perigosa no que concerne a relações de sigilo e anonimato, de modo que se compunham como dispositivos maquínicos importantes quando de seus itinerários. Para alguns, estes dispositivos significavam exposição e risco de serem descobertos por suas famílias, para outros, as mídias exigiam um complexo jogo estratégico de lidar com a produção de imagens e descrições que não lhe causassem danos, e sim uma maior circulação e captação de clientes.

Considera-se que, em termos metodológicos, a articulação entre às vivências etnográficas e o conceito de Comunidades de Prática pode colaborar para uma percepção das comunidades não centrada em aspectos estáticos, mas sim numa composição dinâmica e situacional que pode ser articulada com o marco das interseccionalidades. Neste sentido, o olhar para as práticas comunitárias exigiu descentrar a figura dos Garotos de Programa e identificar sua relação com outros aspectos de sociabilidade, assim como a articulação com interseccionalidade possibilitou atentar para a constituição de espaços de criatividade e produção que não se dão fora de uma relação dialógica e discursiva.

\section{Referências}

Badinter, E. (1993). XY: sobre a Identidade Masculina. Rio de Janeiro: Nova Fronteira.

Barreto, V. (2012). "Vamos fazer uma sacanagem gostosa?" Uma etnografia do desejo e das práticas da prostituição masculino carioca (Dissertação de Mestrado). Universidade Federal Fluminense, Niterói.

Brasil, Ministério do Trabalho. (2014). Classificação Brasileira de Ocupações. Retirado de http://www.mtecbo.gov.br/cbosite/pages/pesquisas/BuscaPorTitul oResultado.jsf

Burbulhan, F., Guimarães, R. M., Bruns, M. A. T. (2012). Dinheiro, afeto, sexualidade: a relação de prostitutas com seus clientes. Psicologia em Estudo, 17(4), 669-77.

Butler, J. (2002). Cuerpos que importan - Sobre os límites materiales y discursivos del "sexo". Buenos Aires, Barcelona, México: Paidós.

Cantalice Silva Trindade, T. (2009). Dando um banho de carinho! Os caça-gringas e as interações afetivo-sexuais em contextos de viagem turística (Pipa RN) (Dissertação de Mestrado). Universidade Federal de Pernambuco.

Daich, D. (2012). ¿Abolicionismo o reglamentarismo? Aportes de la antropología feminista para el debate local sobre la prostitución. Runa, 33(1), 71-84. 
Haraway, D. (1995). Saberes localizados: a questão da ciência para o feminismo e oprivilégio da perspectiva parcial. Cadernos Pagu, 5(5), 7-41.

Hirata, H. \& Kergoat, D. (2007). Novas configurações da divisão sexual do trabalho. Cadernos de Pesquisa, 37(132), 595-609.

Magliano, M. J. (2015). Interseccionalidad y migraciones: potencialidades y desafíos. Revista Estudos Feministas, 23(3), 691-712.

Miskolci, R. (2012). A Teoria Queer e a Sociologia: o desafio de uma analítica da normalização. Sociologias, 11(21), 150-182.

Olivar, J. M. N. (2010). Guerras, trânsitos e apropriações: políticas da prostituição feminina a partir das experiências de quatro mulheres militantes em Porto Alegre (Tese de Doutorado). Universidade Federal do Rio Grande do Sul, Porto Alegre.

Perlongher, N. (2008). O negócio do michê (2. ed.). São Paulo: Fundação Perseu Abramo.

Piscitelli, A. (2008). Interseccionalidades, categorias de articulação e experiências de migrantes brasileiras. Sociedade e cultura, 11(2), 263-274.

Piscitelli, A. (2012). Feminismos y prostitución en Brasil: una lectura a partir de la antropología feminista. Cuadernos de Antropología Social, 36, 11-31.

Pocahy, F. A. (2011). Entre vapores e dublagens: dissidências homo/eróticas nas tramas do envelhecimento (Tese de Doutorado). Universidade Federal do Rio Grande do Sul, Porto Alegre.

Souza Neto, E. N. (2009). Entre boys e frangos: análise das performances de gênero de homens que se prostituem em Recife (Dissertação de Mestrado). Universidade Federal de Pernambuco, Recife.

Streeck, W. (2012). How to study contemporary capitalism? European Journal of Sociology/Archives Européennes de Sociologie, 53, 1-28.

Teixeira, A. E. (2011). Representação sobre a atividade de garotos de programa em Belo Horizonte (MG): emprego, trabalho ou profissão? XI Congresso Luso Afro Brasileiro de Ciências Sociais.

Torrão Filho, A. (2005). Uma questão de gênero: onde o masculino e o feminino se cruzam. Cadernos Pagu, 24, 127-152.

Viana, N. J. Q. (2010). É tudo psicológico/dinheiro/pruuu e fica logo duro! desejo, excitação e prazer entre boys de programa com práticas homossexuais em Recife (Dissertação de Mestrado). Universidade Federal de Pernambuco, Recife.

Vigoya, M. V. (2008). Memorias del 1er. Encuentro Latinoamericano y del Caribe La sexualidad frente a la sociedad. México, D.F. 
Welzer-Lang, D. (2001). A construção do masculino: dominação das mulheres e homofobia. Revista Estudos Feministas, 9(2), 460482.

Wenger, E. (2000) Communities of Practice and Social Learning Systems. Wenger Organization, 7(2), 225-246.

\section{Endereço para correspondência \\ Cristiano Hamann}

Universidade Federal do Rio Grande do Sul - UFRGS

Programa de Pós-Graduação em Psicologia Social e Institucional

Ramiro Barcelos, 2600, CEP 90035-003, Porto Alegre - RS, Brasil

Endereço eletrônico: cristiano.hamann@gmail.com

\section{Adolfo Pizzinato}

Universidade Federal do Rio Grande do Sul - UFRGS

Programa de Pós-Graduação em Psicologia

Ramiro Barcelos, 2600, CEP 90035-003, Porto Alegre - RS, Brasil

Endereço eletrônico: adolfopizzinato@hotmail.com

\section{Kátia Bones Rocha}

Pontifícia Universidade Católica do Rio Grande do Sul - PUCRS

Programa de Pós-Graduação em Psicologia

Av. I piranga, 6681, CEP 90619-900, Porto Alegre - RS, Brasil

Endereço eletrônico: katiabonesrocha@gmail.com

Recebido em: 13/06/2016

Reformulado em: 21/09/2017

Aceito em: 21/09/2017

\section{Notas}

* Mestre em Psicologia Social pela Pontifícia Universidade Católica do Rio Grande do Sul. Doutorando em Psicologia Social e Institucional UFRGS.

** Doutor em Psicologia da Educação pela Universitat Autònoma de Barcelona. Professor Titular da Universidade Federal do Rio Grande do Sul.

*** Doutora em Psicologia Clinica i de la Salut pela Universidade Autônoma de Barcelona. Professora Titular da Pontifícia Universidade Católica do Rio Grande do Sul.

${ }^{1}$ Algumas saunas são especializadas em receber público homossexual. A sauna em questão, além de figurar entre as que se dedicam a este público, promove um espaço onde o sexo mediado por tarifas é incentivado.

${ }^{2} \mathrm{~A}$ clientela fixa se diferencia por um maior compromisso e envolvimento afetivo indicado pelos homens que se dedicavam ao sexo tarifado ao longo da pesquisa.

3 Nesta dimensão de estudo, utilizamos as siglas HST (para Homens que se dedicam ao Sexo Tarifado); Gerência e Clientes, de modo a contemplar alguns aspectos relacionais que são compreendidos neste estudo como constituintes em articulações comunitárias.

${ }^{4}$ As expressões entre aspas são provenientes de falas de participantes.

Este artigo de revista Estudos e Pesquisas em Psicologia é licenciado sob uma Licença Creative Commons Atribuição-Não Comercial 3.0 Não Adaptada. 